\title{
Biochemical indicators of soil fertility in vineyards with different conservative management systems
}

\author{
Claudio Mondini ${ }^{1, *}$, Giovanni Bigot ${ }^{2}$, Tania Sinicco ${ }^{1}$, and Davide Mosetti ${ }^{2}$ \\ ${ }^{1}$ CREA Research Centre for Viticulture and Enology, Branch of Gorizia, 34170 Gorizia, Italy \\ ${ }^{2}$ Perleuve Srl, 34071 Cormons (GO), Italy
}

\begin{abstract}
Biochemical parameters are particularly suited to evaluate soil fertility because soil microorganisms play a pivotal role in determining soil quality and functionand are very sensitive to changes in soil management and environmental conditions. For such reasons, in this work, we used several biochemical indexes to assess the effect on soil fertility of 3 different conservative management systems of vineyards. The managements compared were chemical weed control vs permanent grass (CWC/MWC), land levelling vs undisturbed soil (LL/US), conventional farming vs organic farming (CON/ORG). The following parameters were determined in 2014 and 2015 on soil samples: total organic $\mathrm{C}$ (TOC), extractable $\mathrm{N}(\mathrm{EN})$, soil basal respiration (SBR), microbial biomass $\mathrm{C}\left(\mathrm{B}_{\mathrm{C}}\right)$, microbial quotient $\left(\mathrm{B}_{\mathrm{C}} / \mathrm{TOC}\right)$ and metabolic quotient $\left(\mathrm{qCO}_{2}=\mathrm{SBR} / \mathrm{B}_{\mathrm{C}}\right)$. Results showed that biochemical indicators were effective in detecting changes in soil fertility between compared systems. In particular, conservative systems (MWC, US and ORG) showed a larger and more efficient microbial biomass and enhanced $\mathrm{EN}$ content in comparison to the relative conventional systems. Furthermore $\mathrm{B}_{\mathrm{C}} / \mathrm{TOC}$ and $\mathrm{qCO}_{2}$ indicated higher $\mathrm{C}$ use efficiency in conservative systems. Results as a whole indicate that conservative management systems aimed to maintain and enhance soil organic matter displayed a higher level of soil fertility.
\end{abstract}

\section{Introduction}

Most European vineyards are characterized by soils with low fertility with a negative impact on plant status, productivity, and crop quality [1]. This is exacerbated by the general loss of soil organic matter (SOM) in vineyards that have been recorded in the last decades due to both the intensification of agricultural practices and climate change. A decrease of SOM in vineyards is associated with a decline in soil fertility and could represent the onset of several soil degradative processes, such as erosion, soil compaction, leaching of ions and loss of biodiversity. A possible solution to this problem could be represented by conservative agriculture which is a sustainable agriculture production system aimed to protect the soil from degradation, improve its quality and biodiversity, and contribute to the preservation of the natural resources, while optimizing yields. In particular, conservative agriculture in viticulture is based on soil management, such as minimum tillage and permanent grass cover, which favours the maintenance and enhancement of SOM.

For an effective and affordable introduction of conservative systems in viticulture it is, however, necessary to have indicators that are able to sensitively detect changes in SOM trajectory and in the general fertility status of the soil.
In this context, biochemical indicators (i.e. indicators related to the chemical processes and substances which occur within living organisms) are ideal tools to assess the level of soil fertility [2].

This is because active and healthy soil microorganisms are essential to ensure a good level of soil fertility. Soil microorganisms (collectively the soil microbial biomass) are all soil organisms with a volume of less than $5 \times 10^{3} \mu \mathrm{m}^{3}$ and represent the living pool of SOM. They play a pivotal role in important soil processes such as nutrient cycling, organic matter decomposition, water regulation and decontamination of xenobiotics.

Secondly, being living organisms with intimate contact with soil microenvironments, soil microorganisms are very sensitive and respond much more quickly to changing soil conditions than does soil organic matter as a whole. As such, the microbial biomass can serve as an early warning of such changes long before they are detectable in other ways.

Finally, biochemical indicators are usually easy to determine, do not require sophisticated and costly instruments or particularly skilled operators and are much less expensive with respect to physical and chemical parameters.

For the above reasons, biochemical indicators are ideal tools to evaluate soil quality and health and to 
detect early changes in soil fertility due to variations in management.

The main objective of this work was the use of biochemical indexes to evaluate the effects on soil fertility of different conservative management systems of vineyards.

\section{Materials and methods}

For this study, field trials were established and performed during 2014 and 2015 in the hilly area of the Friuli Venezia Giulia region (North East Italy) in 3 different vineyards located in the AOC Colli Oriental del Friuli.

Vineyard 1 (V1), located at $46^{\circ} 02^{\prime} 47.3^{\prime \prime} \mathrm{N}, 13^{\circ} 25^{\prime}$ 47.9" $\mathrm{E}$ in the hilly area of Ipplis, was planted in 1998 with Carmenere. The plant density is $2.5 \mathrm{~m}$ between rows and $1 \mathrm{~m}$ between vines (ca 4000 vines ha $\mathrm{a}^{-1}$ ).

Vineyard 2 (V2), located at $46^{\circ} 00^{\prime} 36.7^{\prime \prime} \mathrm{N}, 13^{\circ} 27^{\prime}$ 21.7" E in the hilly area of Prepotto, was planted in 1995 with Sauvignon blanc. The plant density is $2.4 \mathrm{~m}$ between rows and $0.75 \mathrm{~m}$ between vines (ca 5500 vines ha $^{-1}$ ).

Vineyard 3 (V3), located at $46^{\circ} 00^{\prime} 29.3^{\prime \prime} \mathrm{N}, 13^{\circ} 22^{\prime}$ $33.2^{\prime \prime} \mathrm{E}$ in the hilly area of Manzano, was planted in 1973 with Chardonnay and Pinot grigio. The plant density is $3.0 \mathrm{~m}$ between rows and $1.2 \mathrm{~m}$ between vines (ca 2770 vines ha ${ }^{-1}$ ).

The soils are classified according to WRB [3] as Cutani-Chromic Luvisols for V1 and Ari-Leptic Regosols for both V2 and V3.

The following soil vineyard management were compared:

- V1: chemical weed control vs permanent grass cover (CWC/MWC)

- V2: land levelling vs undisturbed soil (LL/US)

- V3: conventional farming vs organic farming (CON/ORG)

For each paired comparison, an unbalanced randomized complete block design with three replicates for each treatment was set. Each experimental plot constituted of 10 vines.

At bud break of both years of the trial, 6 soil subsamples were collected from each plot at a $5-25 \mathrm{~cm}$ depth with an auger and merged to obtain a composite soil sample. Samples were sieved moist $(2 \mathrm{~mm})$ and stored at $4{ }^{\circ} \mathrm{C}$ until analysis. Soil samples were analysed for total organic $\mathrm{C}$ (TOC), extractable $\mathrm{N}(\mathrm{EN})$, soil basal respiration (SBR) and microbial biomass $\mathrm{C}\left(\mathrm{B}_{\mathrm{C}}\right)$. TOC

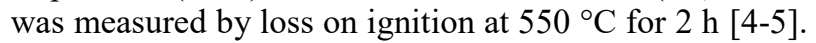
Extractable $\mathrm{N}$ was determined following extraction using a $1: 4(\mathrm{w} / \mathrm{v})$ ratio of soil to $0.5 \mathrm{M} \mathrm{K}_{2} \mathrm{SO}_{4}$ solution. $\mathrm{N}$ content in the extracts was measured using a TOC-TN analyzer (TOC-VCSN Shimadzu). Soil basal respiration was determined every $6 \mathrm{~h}$ using a system for automated sampling and measurement (by gas chromatography) of the headspace $\mathrm{CO}_{2}$ accumulated in closed soil mesocosms incubated at $20{ }^{\circ} \mathrm{C}$ for 10 days. Microbial biomass $\mathrm{C}$ was determined by the fumigation-extraction method [6].
Furthermore the following two quotients were calculated:

i) microbial quotient $\left(\mathrm{B}_{\mathrm{C}} / \mathrm{TOC}\right)$, defined as the ratio between microbial biomass $\mathrm{C}$ and total soil organic carbon [7].

ii) metabolic quotient $\left(\mathrm{qCO}_{2}, \mathrm{SBR} / \mathrm{B}_{\mathrm{C}}\right)$ which is the ratio between soil basal respiration rate and microbial biomass $\mathrm{C}$, representing the hourly amount of $\mathrm{CO}_{2}-\mathrm{C}$ produced per unit of microbial biomass $\mathrm{C}$ [8].

\section{Results and discussion}

Microbial biomass content was higher in conservative managements with respect to conventional ones in both years (Figure 1).
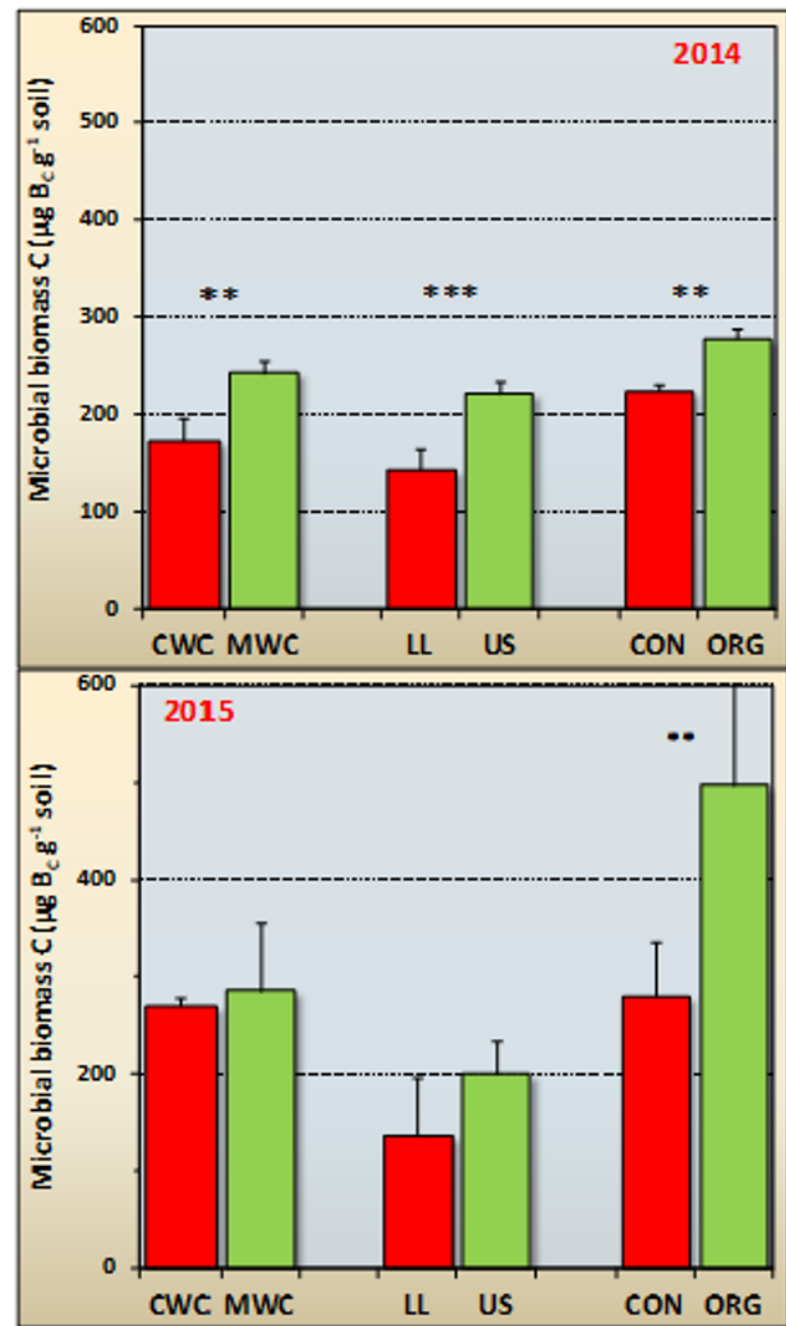

Fig. 1. Microbial biomass $C\left(B_{C}\right)$ in conservative and conventional systems in 2014 and 2015. CWC: chemical weed control, MWC: permanent grass cover, LL: land levelling, US: undisturbed soil, CON: conventional farming, ORG: organic farming. Bars represent standard deviation $(n=3)$. For each pair of treatments, $*, * *$ and $* * *$ indicate significant differences between treatments at $0.05,0.01$ and 0.005 significance level, respectively ( $\mathrm{T}$ test).

Particularly relevant is the increase in microbial biomass recorded in organic managed vineyard in the second year of the trial (497 and $280 \mu \mathrm{g} \mathrm{B}_{\mathrm{C}} \mathrm{g}^{-1}$, for ORG and CON, 
respectively). Soil microbes play many key roles in eco system functions. One primary role is in governing the many nutrient cycles that are essential for the maintenance of soil fertility. A larger content of microbial biomass is an indication that such processes are carried out with higher intensity. Evidence of the enhancement of nutrient cycling in conservative soil managements is represented by EN content. Extractable $\mathrm{N}$ is consistently higher in the conservative systems (MWC, US, ORG) in comparison to conventional ones (CWC, LL, CON) in both years, with the unique exception of MWC in 2015 that was not significantly different from CWC (Figure 2).

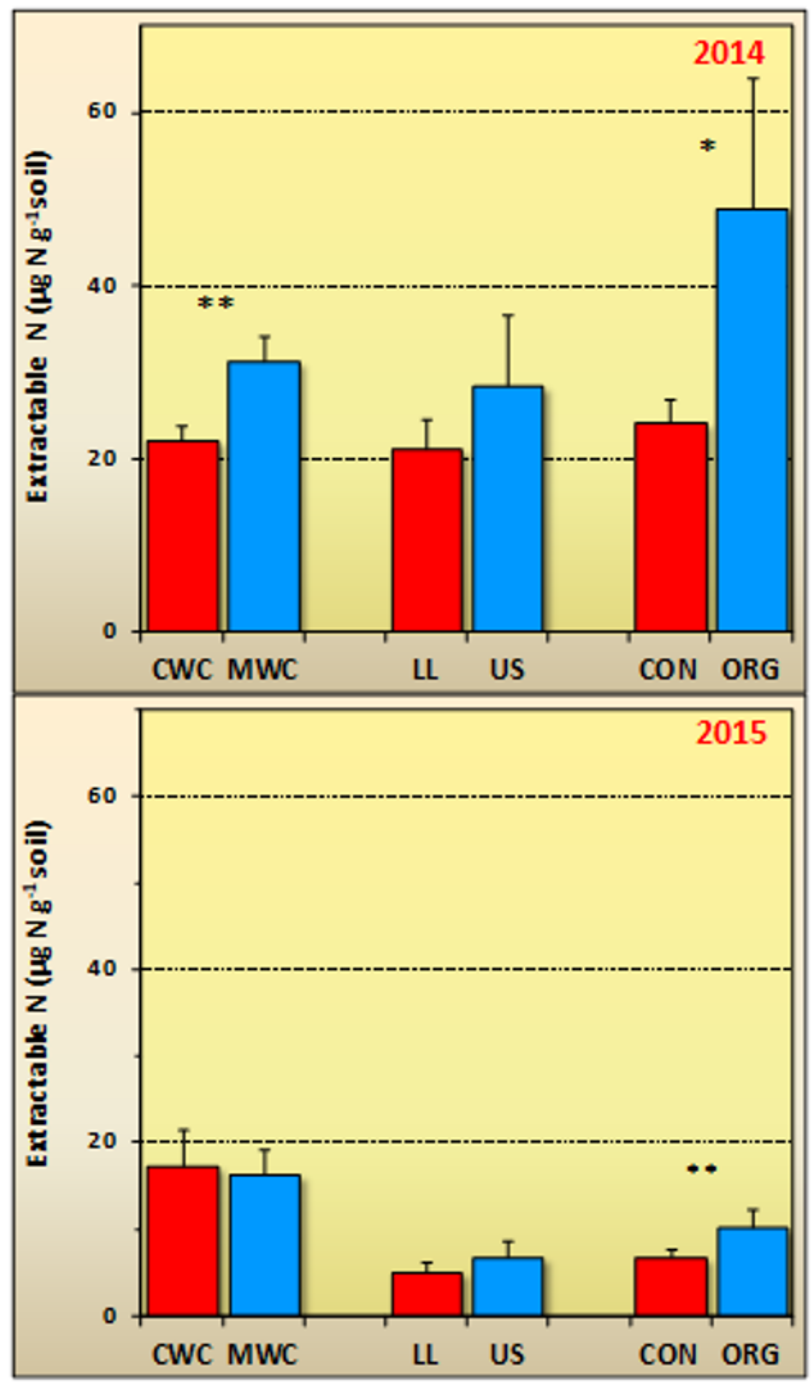

Fig. 2. Extractable $\mathrm{N}$ in conservative and conventional systems in 2014 and 2015. CWC: chemical weed control, MWC: permanent grass cover, LL: Land levelling, US: Undisturbed soil, CON: conventional farming, ORG: organic farming. Bars represent standard deviation $(n=3)$. For each pair of treatments, $*, * *$ and $* * *$ indicates significant differences between treatments at $0.05,0.01$ and 0.005 significance level, respectively ( $\mathrm{T}$ test).

Extractable $\mathrm{N}$ comprises both organic $\mathrm{N}$ and mineral $\mathrm{N}\left(\mathrm{NH}_{4}{ }^{+}\right.$and $\left.\mathrm{NO}_{3}{ }^{-}\right)$. Hence, extractable $\mathrm{N}$ represents the primary source of mineralisable and readily available $\mathrm{N}$. For this reason it has been used as an indicator of changes in soil and fertilizer management. The increase in extractable $\mathrm{N}$ assures the supply of constant but not excessive $\mathrm{N}$ to vines that is important to achieve high quality grapes and must, as supported by findings of Morlat and Morlat and Symoneaux [9-10] in a long term experiment (28 years) of organic amendment. The authors found that supplying high amounts of $\mathrm{N}$ was not beneficial in terms of grape productivity and must quality and is likely to produce toxic effects for the plants, whereas moderate rates were found more suited for sustainable viticulture.

Moreover, higher availability of $\mathrm{N}$ ensures an appropriate decomposition of organic residues entering the soil, avoiding problems related to the decomposition of native SOM and soil $\mathrm{N}$ immobilization in the case of organic residues with a large $\mathrm{C} / \mathrm{N}$ ratio.

Potential problems in utilizing biochemical indicators are the normal seasonal variability in microbial properties and the lack of reference values that sometimes make correct interpretion of the results of the analyses difficult. Such problems could be overcome by the calculation of ratios between different parameters. It has been shown that parameters that have some form of "internal control", e.g. biomass as a percentage of soil organic matter, are advantageous [2]. This is because, for a given climate and soil type and management, such ratios provide a reference value to which comparisons can be made to detect changes in the management or in environmental conditions. Similarly, combining microbial activity and content (e.g. biomass specific respiration) appears to provide more sensitive indications than the parameters alone [2]. In the present work, two ratios were calculated; namely microbial $\left(\mathrm{B}_{\mathrm{C}} / \mathrm{TOC}\right)$ and metabolic $\left(\mathrm{qCO}_{2}\right)$ quotients, which may give clear indication of the microbial use efficiency (CUE) of available resources. Microbial $\mathrm{C}$ use efficiency reflects the capacity of soil microorganisms to form new biomass (cell growth and division), rather than use the available substrate for respiration. CUE is affected by SOM content and availability and environmental conditions.

In the present study, the microbial quotient $\left(\mathrm{B}_{\mathrm{C}} / \mathrm{TOC}\right)$ was consistently higher in the conservative soil systems in both years of the study, with the only exception of ORG in 2014, that was not significantly different from CON. $B_{C}$ is generally in the range of $1-4 \%$ of TOC [2]. In the present work, the microbial quotient in the organic vineyard in 2015 was near the upper part of the range (3.7\%). In US and MWC it was about $2 \%$ and higher with respect to LL and CWC, respectively (Figure 3 ). 


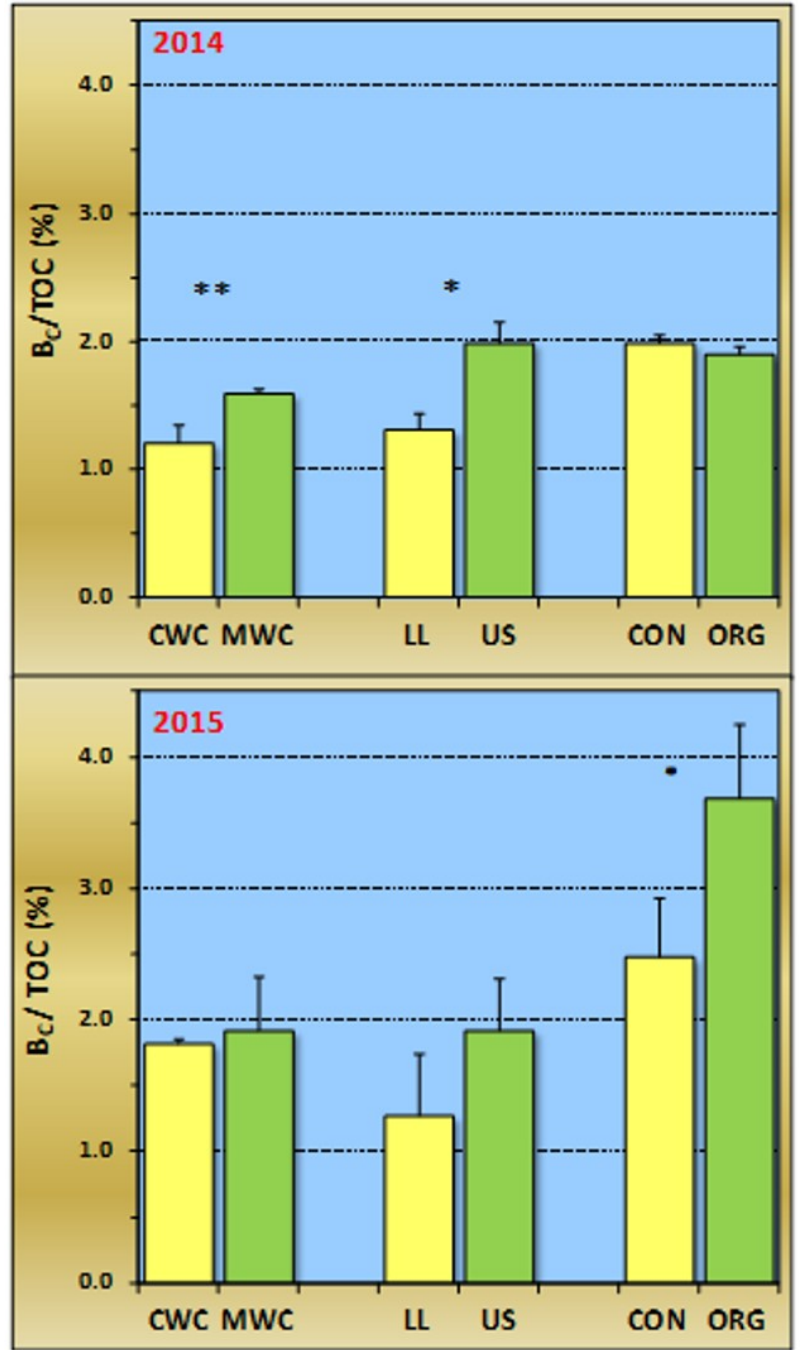

Fig. 3. Microbial quotient (microbial biomass $\mathrm{C}\left(\mathrm{B}_{\mathrm{C}}\right) / \mathrm{TOC}$ ) in conservative and conventional systems in 2014 and 2015. CWC: chemical weed control, MWC: permanent grass cover, LL: Land levelling, US: Undisturbed soil, CON: conventional farming, ORG: organic farming. Bars represent standard deviation $(n=3)$. For each pair of treatments, $* * *$ and $* * *$ indicates significant differences between treatments at 0.05 , 0.01 and 0.005 significance level, respectively (T test).

Microbial quotient indicates the amount of $\mathrm{C}$ substrates available for microbial biomass and how efficiently such substrates are being used by microorganisms. When the soils show marked variations with respect to what is considered the normal value of the ratio for a particular climate, soil type, and management system, this value becomes an indicator of deterioration and change in the functions of the soil ecosystem.

The lower values of the microbial quotient in conventional management systems is an indication of a low organic substrate availability and quality in these soils, as substrate content and properties are important factors controlling the microbial growth rate. In soils with low labile $\mathrm{C}$ availability, the CUE of the microbial community is generally low, as the limited $\mathrm{C}$ substrate is mainly used to satisfy energy demands for cell maintenance with little left for growth and division. Recalcitrant SOM substrates also may decrease CUE by increasing the cost of extracellular and intracellular catabolism.

Total organic soil $\mathrm{C}$ and microbial biomass are positively correlated, but microbial biomass, being composed by living organisms, changes much faster in response to variations in soil management that SOM as a whole. Therefore, the increase in the microbial quotient recorded in conservative systems indicates the tendency of such systems to increase the content of SOM in the long period.

The metabolic quotient $\left(\mathrm{qCO}_{2}\right)$ in the first year of the study was significantly higher for MWC and ORG with respect to $\mathrm{CWC}$ and $\mathrm{CON}$, respectively. In the second year of the study all the conservative systems showed lower values of the quotient with respect to the corresponding conventional system, although this difference was not statistically significant for MWC (Figure 4).

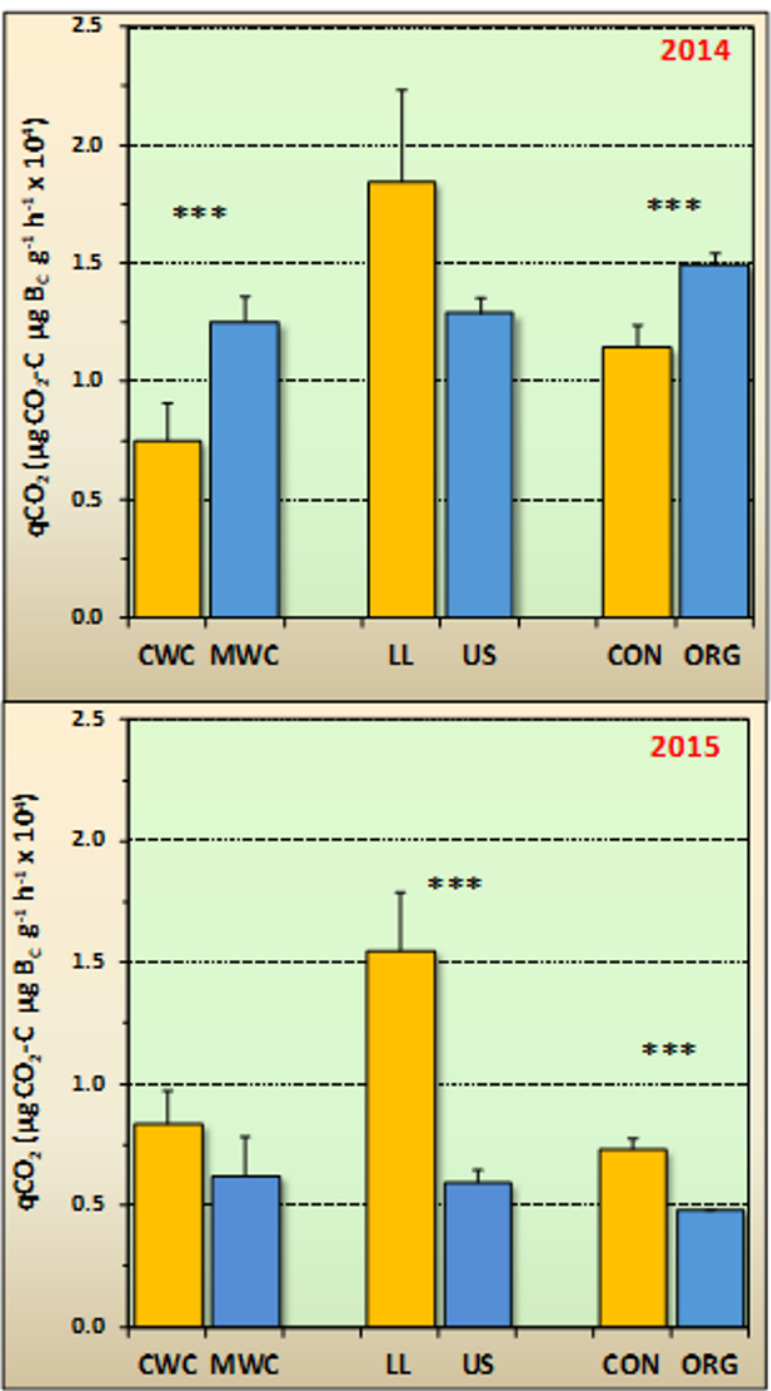

Fig. 4. Metabolic quotient $\left(\mathrm{qCO}_{2}\right)$ in conservative and conventional management systems in 2014 and 2015. CWC: chemical weed control, MWC: permanent grass cover, LL: Land levelling, US: Undisturbed soil, CON: conventional farming, ORG: organic farming, $\mathrm{B}_{\mathrm{C}}$ : microbial biomass $\mathrm{C}$. Bars represent standard deviation $(n=3)$. For each pair of treatments, $* * *$ and $* * *$ indicates significant differences at $0.05,0.01$ and 0.005 significance level, respectively ( $\mathrm{T}$ test). 
The metabolic quotient is an indication of the $\mathrm{C}$ use efficiency of microbial community as it describes how the available $\mathrm{C}$ substrates are portioned between activity for maintenance and growth. As such, it is utilized as an index of the occurrence of environmental conditions of stress (permanent) or disturbance (temporary) and, in general, as a gauge of stability and resilience of ecosystems. A low $\mathrm{qCO}_{2}$ value suggests an efficient $\mathrm{C}$ use by microorganisms. On the other hand, environmental stress causes the soil microbial biomass to redirect more available $\mathrm{C}$ from growth and division into maintenance to tackle the adverse conditions [11], so that an increased proportion of $\mathrm{C}$ taken up by the biomass is respired as $\mathrm{CO}_{2}$, leading to a less efficient use of available $\mathrm{C}$. The lower values of the metabolic quotient recorded in the second year of the trial for conservative systems, as opposed to conventional ones, are a clear indication that the former are characterized by a more efficient use of the resources, therefore leading to an increased sustainability of the vineyard management.

Understanding soil microbial partitioning of organic substrates between respiration and growth in response to different soil management practices affecting SOM content and quality could provide useful information to design sustainable strategies for ecosystem management to enhance soil fertility and $\mathrm{C}$ storage.

Among the conservative management systems, the organically managed vineyards present higher levels of fertility as indicated by biochemical indicators. This in not unexpected because, in opposition of the other two conservative systems under study (MCW and LL), organic management is a more comprehensive management system impacting several aspects of soil fertility.

\section{Conclusions}

Results of the present study clearly showed that soil management systems more concerned with the achievement and maintenance of an appropriate SOM content (ORG, MWC, US) present a larger and more efficient microbial biomass and higher contents of available $\mathrm{N}$, suggesting a higher level of fertility with respect to conventional soil management in vineyards.

The research output underlined the effectiveness of biochemical indicators in discriminating different levels of soil quality and function in vineyard soils, with results that are stable in different years.

Biochemical indicators may represent useful tools to design effective soil management leading to an increased sustainability of vineyards.

The authors would like to acknowledge Emanuela Vida for her technical skill in performing analyses.

\section{References}

1. H.-P. Schmidt, C. Kammann, C. Niggli, M.W.H. Evangelou, K.A. Mackie, S. Abiven, Agric. Ecosyst. Environ. 191, 117-123 (2014)

2. P.C. Brookes, Biol. Fertil. Soils 19, 269-279 (1999)
3. WRB, World Refernce Base for Soil Resources (FAO, 1998)

4. C. Periè, R. Ouimet, Can. J. Soil Sci. 88, 315325(2008)

5. X. Wang, J. Wang, J. Zhang, PLoS ONE 7(8), e44334 (2012)

6. E.D. Vance, P.C. Brookes, D.S. Jenkinson, Soil Biol. Biochem. 19, 703-707 (1987)

7. C.E. Pankhurst, C.A. Kirkby, B.G. Hawke, B.D. Harch, Biol. Fertil. Soils 35, 189-196 (2002)

8. T.H. Anderson, K.H. Domsch, J. Plant. Nutr. Soil Sci. 149, 457-468 (1986)

9. R. Morlat, Am. J. Enol. Vitic. 59, 364-374 (2008)

10. R. Morlat, R. Symoneaux, Am. J. Enol. Vitic. 59, 375-386 (2008)

11. K. Killham, M. Firestone, Appl. Environ. Microbiol 47, 301-306 (1984) 